\section{Influenza $B$}

The total of cases of influenza B detected was small, and the figures shown in Tables I and II do not suggest that infection was widespread in any particular part of the country. Evidence of infection was obtained mainly from the South; no cases were detected in the Northern and North Midland areas, but this may be due to the relatively small numbers of specimens from these areas.

The most striking features shown by the figures are the absence of any peak and the observation of positive results throughout a period of almost eight months. Whereas in the case of influenza A there was a sharp peak, and although a much greater number of cases were detected, all the positive results occurred in a period of four months. It is interesting to notice also that cases of influenza $B$ have been detected in three of the last four years.

\section{Virus Isolations}

Distribution and Antigenic Groups of the Virus Strains Isolated

Most of the above discussion is based on serological results. In all, 106 strains of influenza virus A were isolated, and the figures arranged by weeks and regions in Table II give a similar picture to those for sera in Table $I$. The aim was to provide a representative selection of strains from the various regions and at different stages of the epidemic. Several strains were obtained in each of the RegistrarGeneral's regions, and the 106 isolations represent 62 different localities. The interval between first and last strains isolated was 13 weeks, and in most regions four or five weeks elapsed between the first and last isolations, so that it may be fairly claimed that the aims mentioned above were achieved.

In 1951 two antigenic groups of influenza $A$ were present in the country, and exact information regarding their distribution was rather scanty. During the past winter, virus isolations were undertaken on a relatively large scale so that in the event of more than one antigenic group being present adequate material would be available for epidemiological studies. Strains of influenza viruses sent from the Public Health Laboratory Service laboratories to the World Influenza Centre have all, with one exception, been closely related to, but not identical with, the Scandinavian group strains isolated in England in 1951. The exception was one of several strains isolated from patients in the Ipswich (Suffolk) area, and was related to the Liverpool group strains, which were also present in England in 1951. A second strain of this group was isolated at the World Influenza Centre, London, from a member of their staff.

Strains of the 1953 Scandinavian group were also found this year in Japan, the U.S.A., and Western Europe, and Liverpool group strains were isolated in Paris, Switzerland, and Portugal.

Included in the figures for virus isolations were 28 specimens of lung obtained post mortem. Two strains each of influenza $A$ and $B$ were recovered from these specimens, and it is interesting to note that both the $\mathbf{A}$ strains were from patients in the London area who had died suddenly during the fogs of December and January respectively. Twelve other specimens of lung from patients in the same area whose death was also believed to be associated with fog were negative in virus isolation tests.

\section{Summary}

The laboratory evidence for influenza virus infections in England and Wales during the winter of 1952-3 is presented and analysed according to regions and the date of collection of specimens.

The first cases of influenza A were detected in midDecember, and the disease became epidemic at the end of January-that is, four to six weeks after the first evidence of infection was obtained.
In the country as a whole there was close agreement between estimates of the time limits of the epidemic derived from the laboratory results, the RegistrarGeneral's weekly returns for deaths from influenzal pneumonia, and increased claims for sickness benefit received by local offices of the Ministry of National Insurance and Pensions.

The evidence suggests that the influenza A epidemic spread northwards from the south-east and south.

A few cases of influenza B infection were detected during most weeks between mid-January and mid-May, and occasional cases were detected up till August.

106 strains of influenza virus A were isolated, and these were well distributed with regard to time and place.

Information regarding the antigenic groups of influenza virus $A$ was kindly supplied by Dr. A. Isaacs, of the World Influenza Centre, London. Figures for deaths from influenzal pneumonia are quoted from the Registrar-General's weekly returns, published in the British Medical Journal. The figures for local offices of the Ministry of National Insurance and Pensions were calculated from data made available by and quoted with the kind permission of Dr. A. Massey, Chief Medical Officer of the Ministry of National Insurance and Pensions.

\section{REFERENCES}

Logan, W. P D. (1951), Proc, roy, Soc. Med., 44, 792. Massey, A. (1951). Ibid., 44, 790.

\section{CENTENARY OF HYPODERMIC INJECTION}

\author{
BY
}

\section{G. A. MOGEY, M.B., B.Ch.}

Department of Pharmacology, University of Leeds

Hypodermic, or subcutaneous, injection of drugs being now so catholic, it is surprising to find that of all the common current methods of exhibition this is one of the most recently introduced. Inhalation, rectal administration, and even intravenous infusion were in use when Dr. Alexander Wood, of Edinburgh, gave the first subcutaneous injection, in the modern sense, one hundred years ago. As the present year is the centenary of that injection it may be of timely interest to recall the origins of the method and something of its author.

The modern hollow hypodermic needle and its companion, the syringe, have evolved from earlier and cruder predecessors made when man first began to inject drugs intravenously and to practise blood transfusion. So perhaps the common origin of these procedures is the best point to begin a consideration of the development of hypodermic injection.

\section{The First Blood Transfusion}

Although the ancient Egyptians may have practised it, the first really successful blood transfusion was not performed until the middle of the seventeenth century. The story of the rejuvenation of Aeson by Medea (Ovid, 43 B.C.) is interpreted by some as an indication that the notorious sorceress was acquainted with the method, and that therefore the early Greeks knew of blood transfusion. However, Ovid's description of the rejuvenation simply establishes Medea as an early pharmacologist rather than as the deviser of blood transfusion. It is difficult to be sure whether she should be regarded as the first to inject drugs into the human body, for there were no eye-witnesses-except Liber- 
of the operation, which is reputed to have been done by cutting Aeson's throat and pouring "the juices," prepared from various plants and animals, into his veins. Again, it is often stated that the first transfusion was carried out on Pope Innocent VIII (1432-92) ; but, as Keynes (1949) has pointed out, the papal elixir was simply a draught prepared by a Jewish physician from the blood of three boys who were bled to death for the purpose-at least, they died soon after the bleeding.

Precisely when blood transfusion came into existence is still a matter of dispute, but it is certain that transfusion was preceded by infusion. The earliest attempts at intravenous injection were made in England in the middle of the seventeenth century and were soon followed by infusion of blood into animals and then into man.

\section{Intravenous Injection}

In 1657 Christopher Wren-while he was Savilian Professor of Astronomy at Oxford and before he became famous as an architect-conducted numerous experiments, with the assistance of Robert Boyle and a Dr.

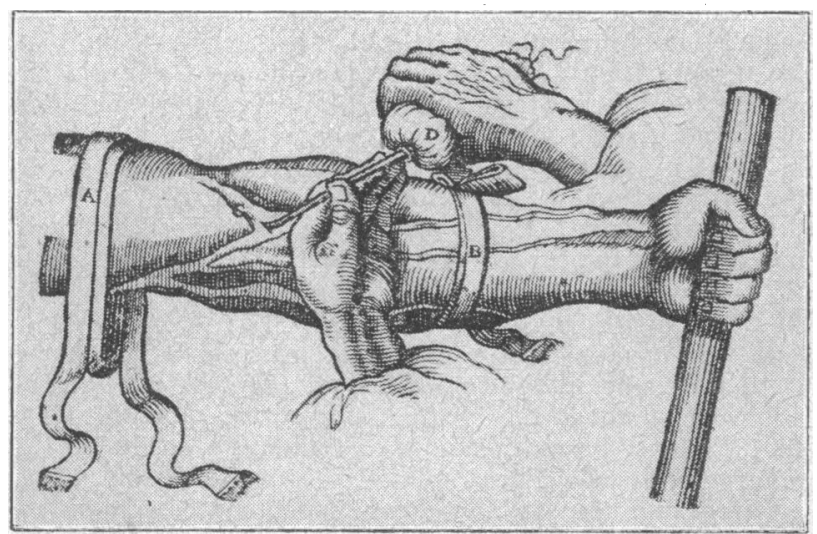

FIG. 1.-Engraving from page 2 of Major's Chirurgia Infusoria. Kiloni, 1667, showing his injection apparatus. (Photograph of engraving kindly supplied by Mr. W. J. Bishop, of the Wellcome Historical Medical Library.)

Wilkins, on the giving of drugs by intravenous injection (Oldenburg, 1665). Bishop Sprat (1702) said of Wren : "He was the first Author of the Noble Anatomical Experiment of Injecting Liquors into the Veins of Animals. .. B By this operation divers Creatures were immediatly purg'd, vomited, intoxicated, kill'd, or reviv'd, according to the quality of the liquor injected: Hence arose many new Eperiments [sic], and chiefly that of Transfusing Blood, which the Society has prosecuted in sundry Instances, that will probably end in extraordinary Success."

Wren appears to have been the first to perform an intravenous injection in man in, it is thought, 1657 (Clarck, 1668). During the injection the victim-a delinquent servant of a foreign ambassador-fainted and the experiment had to be stopped. Boyle (1664) described this experiment in a way which suggested that the foreign ambassador had performed the injection, but Clarck made it quite clear that it was Wren who did it in the house of the Duc de Bourdeaux, the French Ambassador. A few years later, in 1662 , J. D. Major also performed some successful intravenous injections in man (Major, 1664).

For these early injections both of blood and of drugs, a quill, later replaced by a silver or gold tube-the "pipe"-was inserted into the vein and the injection made through it, either by using a small bladder-" like a clyster"-as a pump or by means of a gravity feed. The first injections were chiefly of water, opium, and purging medicines. Intravenous administration of jalap resins, as practised for example by Fabritius (1667), was particularly popular, especially in the treatment of syphilis.

The frequent use of opium led to the early observation that it stupefied dogs and excited cats (Boyle, 1664). But opium and narcotics were by no means the only substances injected intravenously. Fortescue-Brickdale (1904) quoted Purmann (1706) as giving a list of drugs sometimes used. It includes amber, arsenic, cinnamon, oil of sulphur, snail water, spiritus lilior convallarium, spiritus nitrosi vel vitrioli, and spiritus salis ammoniaci.

With only impure drugs and crude apparatus available, the method of intravenous infusion soon fell into disrepute, and for the remainder of the seventeenth century was carried out but sporadically. Very little more was published on the subject until near the end of the eighteenth century, when there was a temporary revival of interest, which continued well into the next century. During this period Magendie was one of those most actively interested : he attempted to treat hydrophobia with injections of opium, or sometimes even warm water (Olmsted, 1944). But little success attended him, and again, except for saline infusion, the practice seems to have been little used until later in the same century, when there was a further revival of interest about 1870 . It was not, however, until the irrepressible Ehrlich showed that intravenous administration of his arsenical compounds really was a practical procedure that it became commonplace in therapeutics.

\section{The Work of Pravaz}

While the practice of intravenous injection of drugs waxed and waned in the nineteenth century a special type of intravascular administration was described. Its originator was Dr. Charles-Gabriel Pravaz (or Pravas), of the Veterinary College in Lyons, France. His method was presented to the Academy of Sciences in Paris on January 10,1853 , by $M$. Lallemand, a director of the College. It was published in the correspondence section of the Academy's proceedings under the title "Sur un nouveau moyen d'opérer la coagulation du sang dans les artères, applicable à la guérison des aneurismes." Pravaz injected iron perchloride " au maximum de concentration" into the vessels of sheep and horses through "un trois-quarts trèsfin or ou en platine" introduced obliquely by "une espèce de mouvement de vrille." "A ce trois-quarts se trouve ajustée une seringue dont le piston doit être à pas de vis, afin que l'injection s'opère sans secousses et que la quantité de liquide injecté puisse être mesurée avec précision."

Pravaz suggested that the method might be modified to render it suitable for the treatment of aneurysms in human beings, and calculated that the injection could be made, with time allowed for clot formation, in about four to five minutes. As he designed and caused a syringe to be made for this work, the erroneous claim, such as that of Fluck (1953), is sometimes advanced that Pravaz was responsible for introducing hypodermic injections : but of this more anon. (Experiments on the coagulation of the blood had been carried out long before the time of Pravaz. For example, Bishop Sprat, in his History of the Royal Society of London (p. 199) says that the Society received a communication telling "of making the blood Florid with Volatil and coagulating with Acid Salts." Presumably he was referring to the work of Fracassati, who, in a communication to the Royal Society in 1667, described such experiments on dogs. Robert Boyle (1667) performed similar investigations on shed blood, and claimed that it was from these experiments that Fracassati got his ideas.) 
Shortly before the work of Pravaz, in a period which coincided with the isolation of the first pure alkaloids from some of the crude drugs used earlier for intravenous injection, a new technique of administering medicinal agents had been evolved. In it the drugs were not-given direct into the circulation, but were placed beneath the skin, from which site they gradually found their way into the system. And even prior to this, drugs had been administered through the skin, by the application of ointments and liniments to the epidermis, sometimes accompanied by vigorous rubbing. These methods were not very satisfactory, and neither was their extension-the direct application of drugs to the dermis, following the removal of the epidermis by blistering agents or caustics. Another method, more closely resembling the modern subcutaneous one, was described in 1836 by Lafargue in France. He smeared drug, in the form of paste, on the tip of a vaccination lancet, which was then pushed through the skin, where it remained for a short time before withdrawal. However, as the dose was obviously not determinable, and the method laborious and timeconsuming, it never became popular.

\section{Rynd's Method}

From Dublin, in its heyday as a medical centre while Graves, Stokes, Adams, and Corrigan were leaders of the profession, there came a different approach to the problem of finding a more generally applicable and safer parenteral route of administration than the intravenous. Francis Rynd, surgeon to the Meath Hospital, devised a form of subcutaneous administration of drugs which has a slight claim to be the forerunner of the modern hypodermic method (Rynd, 1845). Under the title "Neuralgia-Introduction of Fluid to the Nerve," he described how, on June 3, 1844, " a solution of fifteen grains of acetate of morphia, dissolved in one drachm of creosote, was introduced to the supra-orbital nerve and along the course of the temporal, malar, and buccal nerves by four punctures of an instrument made for the purpose." He found that the pain of the neuralgia was abolished very rapidly, and that the patient, an elderly lady, had a better sleep the fol-

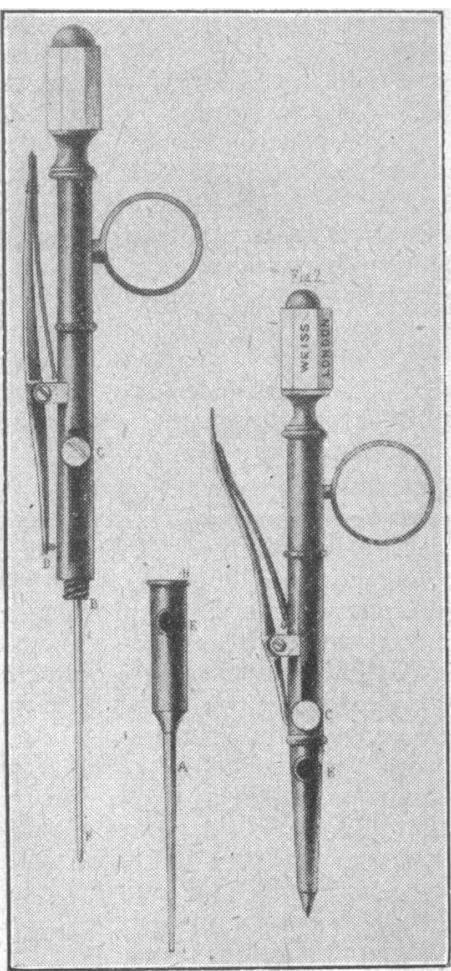

Fig. 2.-The apparatus used by Rynd (from Dublin Quart. J. med. Sci., 1861, 32, 13). lowing night than she had had for months. He also described the case of a man aged 28 , who seems to have had sciatica, successfully treated by a similar technique, although the concentration of morphine was reduced by a third. Rynd did not describe the instrument in this paper and quoted no references. It was not until a good deal later that he published an article giving details of his apparatus (Rynd, 1861), which was essentially a trocar and cannula. After insertion through the skin the trocar was made to spring back out of the cannula into the body of the instrument by pressure on the lever at the side (Fig. 2). The drug solution was then poured in through a small hole near the base of the cannula and allowed to gravitate into the subcutaneous tissues.
- In 1845 a claim was made by Arthur Guinness that on reading Rynd's article he was reminded that "it had been my intention long since to have sent you an account of some cases treated by me during last summer in a similar manner. ... I used a common lancet armed with morphine, mixed in a little water, about the consistence of a paste and operated precisely as is done in vaccinating an infant ; I did not use creosote with it. . . . In another bad case of neuralgia I determined on using creosote without morphine. . . . It was of decided benefit in my case." This technique described by Guinness was not new, for it had been employed eight years earlier by $M$. Lafargue, and in any case it was not the ancestor of the present-day practice of hypodermic injection.

Although Rynd's method of administering fluids has been held by some to be the beginning of modern hypodermic injection (Macht, 1916 ; Pfender, 1911) it is extremely hard to make a really good case for this. Rynd did employ a hollow cannula, which could be regarded as a forerunner of the hollow hypodermic needle, but he depended upon gravity to force the drug solution into the tissues. Further, he was interested only in the local pain-relieving properties of his injections and did not seem to realize that effects remote from the site of injection might be obtained. This is all the more surprising when the doses are known: "The fluid I have found most beneficial is a solution of morphia in creasote [sic], ten grains of the former to one drachm of the latter; six drops of this solution contain one grain of morphia, and a grain or two or more may be introduced in cases of sciatica at one operation". (Rynd, 1861). As the syringe is now an essential component of the hypodermic apparatus, Rynd's instrument was most definitely not a direct forerunner of the modern equipment.

\section{Introduction of the Hypodermic Method}

It was in 1853 that hypodermic injection as we know it to-day came into being, although the first public pronouncement about the method was postponed until 1855 . In $1853 \mathrm{Dr}$. Alexander Wood, of Edinburgh, instituted the practice of injecting drug solutions through the skin, using a syringe and needle. The idea of subcutaneous administration came to him while considering a development of the special type of injection introduced by Pravaz for the treatment of aneurysm. Thus, subcutaneous injection really grew out of earlier intravascular practice. Wood wrote: "Having occasion, however, about the end of 1853, to endeavour to remove a naevus by injection with the acid solution of perchloride of iron, I procured one of the elegant little syringes, constructed for this purpose by $\mathrm{Mr}$. Ferguson of Giltspur Street, London. While using this instrument for the naevus, it occurred to me that it might supply the means of bringing some narcotic to bear more directly than I had hitherto been able to accomplish on the affected nerve in neuralgia. I resolved to make the attempt, and did not Iong lack the opportunity."

An elderly lady who had suffered for a long time from cervico-brachial neuralgia - and who, incidentally, could not take opium in any form by mouth without being violently sick-was the patient who afforded Wood his desired chance. "Accordingly, on November 28th, I visited her at 10 p.m. to give the opiate the benefit of the night. ... I I inserted the syringe within the angle formed by the clavicle and acromion, and injected twenty drops of a solution of muriate of morphia, of a strength about double that of the officinal preparation."

Wood (1855) published this description of the first hypodermic injection in the modern sense under the title "New Method of Treating Neuralgia by the direct application of Opiates to the Painful Points." To the twenty-sixth Annual Meeting of the B.MA., held in Edinburgh in July, 1858 , he stated that the solution injected was "made of morphia in sherry wine, because I thought it would not irritate and smart so much as alcohol, and because it would not rust the instrument as a water solution of opium would do" (Wood, 1858). (Incidentally in this address Wood said 
that his first injection was given in November, 1843, not 1853, and Howard-Jones (1947) doubted that this was a genuine mistake. If accepted it would, of course, give Wood's method priority over that of Rynd.)

Wood injected a solution " of a strength about double that of the officinal preparation." Whether there was any difference between the officinal and official preparations is not certain. This was in the days when the colleges issued their own pharmacopoeias, and it is more than likely that Wood used the then current Edinburgh issue of 1841. In it the Morphiae Muriatis Solutio is prepared by dissolving 5 iss muriate of morphia in a mixture of 5 fluid ounces of rectified spirit and 15 ounces of distilled water. It therefore contained $1 \mathrm{gr}$. $(65 \mathrm{mg}$.) of morphine muriate in 106 minims $(6.4 \mathrm{ml}$.) of solution. So, if Wood injected twenty drops of a solution about double this strength, he gave a dose of about $\frac{2}{5} \mathrm{gr}$. (26 mg.) of morphine hydrochloride.

Although Wood, like Rynd, was interested mainly in the relief of pain in the neighbourhood of the injection, he realized that general effects were important too. His conclusions indicate this quite clearly :

" 1st, That narcotics injected into the neighbourhead [sic] of the painful point of a nerve affected with neuralgia, will diminish the sensibility of that nerve, and in proportion diminish or remove pain.

" $2 d$, That the effects of narcotics so applied are not confined to their local action, but that they reach the brain through the venous circulation, and there produce their remote effects.

" $3 \mathrm{~d}$, That in all probability what is true in regard to narcotics would be found to be equally true in regard to other classes of remedies.

" 4th, That the small syringe affords a safe, easy, and almost painless method of exhibition.

" 5 th, That, destitute as we are of any precise experiments as to the applicability of cellular tissue as a medium for the reception of medicinal agents, the experiments made with the syringe show that it seems to offer an excellent surface for the absorbent action of the venous system."

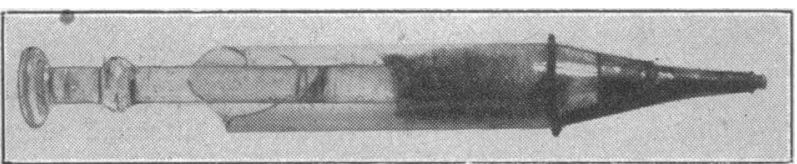

Fig. 3.-Dr.-Alexander Wood's syringe (by courtesy of Mr. J. N. J. Hartley, Curator of the Museum of the Royal College of Surgeons of Edinburgh). Since this photograph was taken the syringe has suffered further damage and the barrel is now shorter than shown here.

These passages make it quite obvious that Wood realized the general applicability of his method. But in spite of this he was mostly concerned with injections at the seat of the pain,. although he believed that both a local anaesthetic effect and the general narcotic action of morphine were of value in the treatment of neuralgia.

The syringe which Wood used is well known and is preserved in the Museum of the Royal College of Surgeons of Edinburgh. There is no trace of the needle (J. N. J. Hartley, personal communication, 1952).

\section{Wood's Syringe and Method of Injection}

Comrie (1927) described Wood's syringe thus: "The syringe is $90 \mathrm{~mm}$. in length, and the barrel, which has been broken towards its base, is $10 \mathrm{~mm}$. in diameter. The piston is wrapped round at its extremity with cotton wick to make the plunger fit the barrel. At its apex the barrel is drawn into a conoidal extremity which fits a metal nose cap. The cap is of curious construction and consists of one inner filler-shaped part which fits closely to the diminishing portion of the glass barrel and ends in a pointed extremity, which is threaded externally, to allow a hypodermic needle to be screwed on. The filler-part is grasped by a metal arrangement, whose apex is tightly applied to it at the screw. It is prolonged upwards by two lateral metal strips, bound by a circle round the middle of the inner cap, and prolonged upwards further by the two lateral bands, to end in a ring, which does not touch the barrel, and may have been used to steady the syringe and prevent the metal cap being forced off during administration of a hypodermic injection."

It is surprising that Wood did not describe the needle, for it is such an important part of the equipment, and differed from anything before it in being attached to the syringe to form a composite instrument. Far from describing the needle, he wrote, in his $\mathbf{1 8 5 5}$ article, about inserting the syringe. However, his biographer, the Rev. Thomas Brown, who married Wood's sister, stated that the design was based on the sting of the bee (Brown, 1886). This information was probably obtained from Wood's description of the type of syringe he was using in 1858, one which had been improved by the addition of graduations to the barrel. "The instrument is of the simplest construction and is a modification of $\mathrm{Mr}$. Ferguson's, already alluded to. It consists of a small glass syringe graduated like a drop measure, and to this is attached a sinall needle, hollow, and having an aperture near the point like the sting of a wasp" (Wood, 1858). These scant statements appear to be the only information about the actual needle used by Wood. The needle is probably more correctly compared to the sting of a wasp than to that of a bee, because of the barbs on the latter. The photograph of the syringe shows that the nozzle was adapted for the application of some kind of needle which screwed on to the metallic male end of the apparatus.

Wood's method of injection was taken up by others in many countries only after his 1858 paper. At first, however. all adhered to the principle of injecting the pain-relieving drug into or near the site of the pain. The demonstration, that to relieve pain the injection of morphine did not have to be at the sore place, was due to a London surgeon, Charles Hunter. He pointed out that repeated injection into "an unsound or morbidly sensitive part" increased the tendency to sepsis, and was accompanied by great pain during the actual injection (Hunter, 1859). He maintained "that, by the introduction of narcotics into the cellular membrane of the body, we have a mode of attacking and subduing cerebral excitability more rapid, more certain, and more pure in its action, than by stomachic doses of narcotics." Hunter described the needle he used, and gave an illustration of it (Fig. 4). The "pipe," as he called it, was

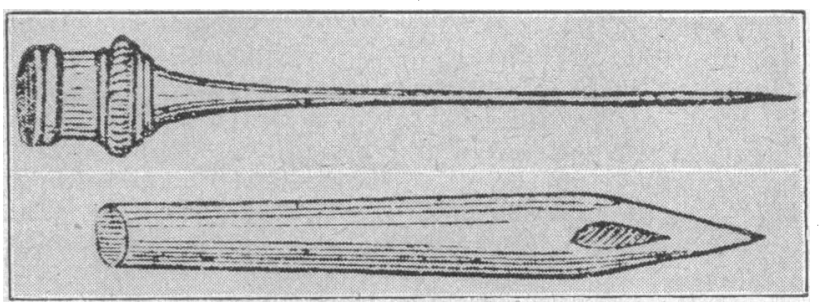

Fig. 4.-Hunter's needle. (From Med. Tms Gaz., 1859, 19, 354.)

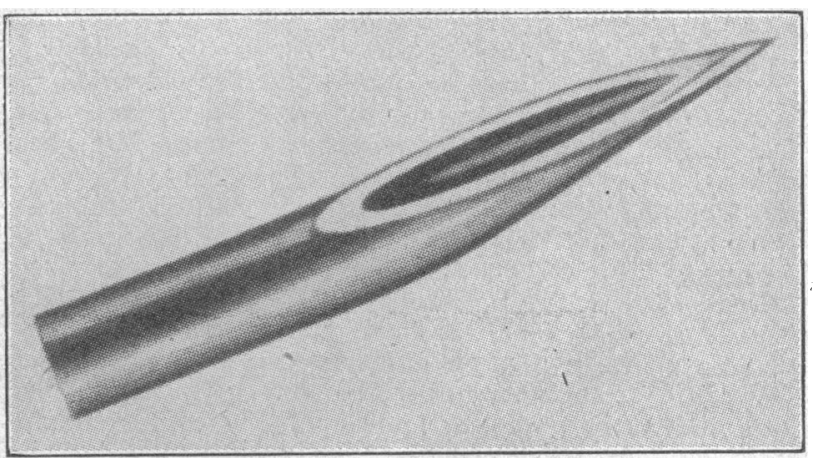

FIG. 5.- The Huber needle. (Reproduced, by permission, from the article by Dr. O. Schwidetzky in Medical Physics, vol. 2, edited by Dr. O. Glasser, Year Book Publishers Inc.) 
made of silver with a hardened gold point. He had two pipes, the smaller of which was about $1 \frac{1}{4}$ in. $(3 \mathrm{~cm}$.) long and about 25 or 26 s.w.G. Each pipe was pointed "like a needle," tapering from all angles as does a pencil point, and occupying a place between the usual hypodermic needle of to-day with its bevelled end and the Huber needle (Fig. 5). Hunter went on to use drugs other than morphine and to develop the grandiose idea of a " hypodermic treatment of disease."

\section{Biographical Notes on Dr. Wood}

Dr. Alexander Wood, who undoubtedly deserves the credit for the introduction of the hypodermic method, was born at Cupar, Fife, on December 10, 1817. He belonged
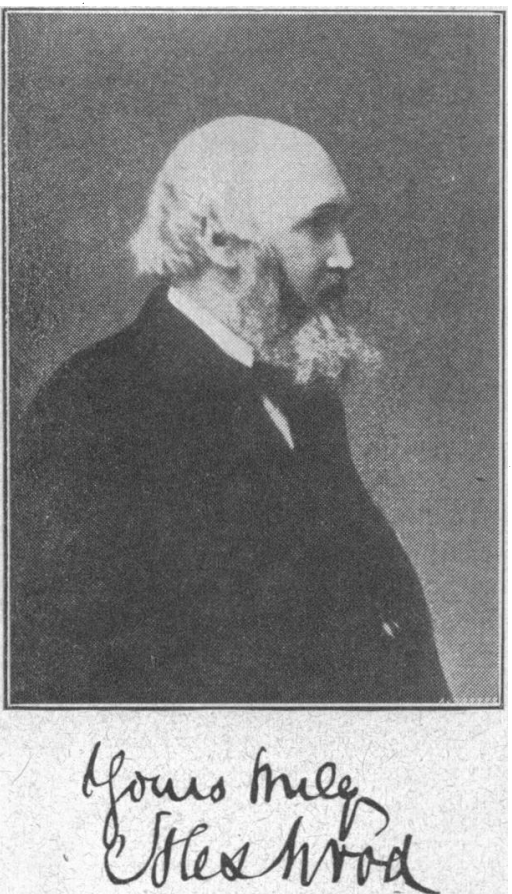

Fig. 6.-Dr. Alexander Wood as an elderly man. (From Dr. Alexander Wood, M.D., by Rev. Thos. Brown, Edinburgh, 1886.)

to a family distinguished medically, and his ancestry has been traced to a Dr. Alexander Wood, "who in 1682 married the daughter and heiress of Jasper Johnston of W a r rist on and Curriehill"'(Brown, 1886). The Alexander Wood of hypodermic fame is often called Secundus to distinguish him from his grand-uncle, an earlier Dr. Alexander Wood (17251807), familiarly known as Lang Sandy. Educated a $\mathrm{t}$ a dvent u re schools until 1826 , Wood Secundus then went to Edinburgh Academy, opened two years earlier. Entering Edinburgh University in July, 1832 he took the usual

Arts course at the same time as he followed the medical curriculum. One of the great men who had a profound effect on Wood at the university was Dr. (later Sir Robert) Christison. Wood was a member of the Royal Medical Society, which he served as Junior President from 1837 to 1839 . He graduated on August 1, 1839. In 1840 he was elected F.R.C.P.Ed., and in 1841 was appointed Lecturer in the Practice of Medicine at the extramural school.

His first published paper was on poisoning with corrosive sublimate $(1839)$; this was followed by others on homoeopathy $(1844,1845)$, mesmerism (1851), and subcutaneous injection (1855). In 1842 he married an Irish lady, Rebecca Massey, of Tipperary; so far as I have been able to find, they had no children. He took a lively interest in medical politics, and was a representative of Scottish medicine on the General Medical Council in London. Elected sixtyseventh President of the Royal College of Physicians of Edinburgh, he remained in this coveted position from December, 1858, to December, 1861. He was a formidable debater at professional meetings, but was very gentle and kind as a teacher in the Sabbath School. His religious habits are certainly not in keeping with the suggestion that he purposely instituted, or knowingly allowed to continue, the false impression that his first subcutaneous injection was performed in 1843 and not 1853 . He died on February 26, 1884.

\section{Terminology}

When Wood introduced the method of injecting drugs below the skin he called it the "subcutaneous" route. When Charles Hunter, as already described, extended the applications of the method he introduced the term "hypodermic." Hunter's reason for giving a new name to his method, which really only withdrew the emphasis from the local action, was, no doubt, that he wanted his "remote" injections to be regarded as something completely new and different from the locally acting injections of Wood and Rynd. Wood and Hunter carried out a long correspondence in the Medical Times and Gazette on the subject of who was the first to recognize the remote effects following an injection (for references, see Howard-Jones, 1947).

The names applied to the injection of fluids under the skin are interesting. Called by Wood "subcutaneous" after the Latin-the word being in use before Wood's time-it was dubbed "upodermic" by Hunter in his first paper on the subject. Upodermic was used because it was of Greek origin and therefore similar to the terms endermic and enepidermic, which were fairly common at that time. In his second paper Hunter used the term "hypodermic," adding a footnote, "In the first part of this paper the word hypodermic was spelt upodermic : but I now spell the word in accordance with common orthography." The most likely reason for Hunter's adoption of the form " upo" is that he did not realize the significance of the rough breathing mark in i $\pi \delta$. Perhaps some colleague with a better classical education pointed out the error in time for it to be changed in the second paper.

It is doubtful if Hunter was right in his choice of name, although he was justified because of the existing words from the same root. The name is derived from $\delta \varepsilon p \mu \alpha \tau i x b s$, not $\delta \varepsilon \rho \mu \alpha$ : the stem is dermat, as in dermatitis and dermatologist. Hence hypodermatic would be more correct than hypodermic. Hypodermic, however, is sanctioned by long usage and has the advantage of being the shorter form.

\section{Early Forms of Hypodermic Syringe}

The Ferguson syringe used by Wood is undoubtedly the forerunner of the modern "hypodermic," although there have been some modifications since it was first used for subcutaneous injection. The needle screwed on to Wood's syringe, and the glass piston, wrapped in cotton-wool or gauze to reduce leaks, was operated by a push-pull action. When hypodermic injection became popular on the continent of Europe, the syringes used were at first based on that which Pravaz had employed for injecting clotting agents into aneurysms. These differed from the FergusonWood type, for the syringe was of metal and the piston was operated by a screw mechanism. The mode of use was also different: with the Pravaz type of syringe, which Béhier popularized in France for subcutaneous injections, a trocar and cannula were inserted through the skin; the trocar was withdrawn and the syringe screwed on to the cannula, which remained in position until the injection was completed.

This method was obviously cumbersome and it was impossible to avoid the injection of air. Besides, when injecting aneurysms, clotting was apt to occur when blood and sclerosing fluid met in the cannula and, when this happened, to cause a leak back past the piston. As most syringes were of silver the leak could not be seen; so, to obviate the difficulty thus caused, Lenoir had a glass barrel made for his syringe. He also introduced the use of a fine second cannula. This was attached to the syringe, charged with fluid, and inserted through the wider first cannula, already placed in position in the tissues. Lenoir's work is well reported in the Association Medical Journal (Report, 1853), but even when his modifications were adopted for subcutaneous injections the method remained complicated and was totally unlike present-day practice. In Wood's 
technique, however, as in the modern hypodermic method, perforation of the skin was effected with the penetrating needle already attached to the syringe.

\section{Advances in Design}

The screw piston remained on Continental syringes until H. Wulfing Luer, a Parisian surgical instrument maker, introduced a metal-and-glass instrument which dispensed with the screw piston and adopted the push-pull mechanism of the Wood apparatus. Luer also rejected the screw mount for the needle, and in this respect set the fashion for the hypodermic syringe as we know it to-day. He did not adopt Wood's addition of graduations to the syringe barrel, but marked the piston-rod instead. Although his syringe had a push-pull mechanism there was a movable stop which traversed a thread along the piston shaft. By setting this stop before injection the dose to be delivered was fixed and could not be exceeded without further manipulation. A similar running stop is still to be found on some present-day syringes.

The next advance in syringes came about 1896, when Luer introduced an all-glass model (Schwidetzky, 1952). Schwidetzky also stated that the first of the familiar Record syringes was made in 1906 by the German firm of Dewitt and Hertz. Though the Record mount is probably the most widely used in this country to-day, it seems likely that it will ultimately be replaced by the Luer mount, which is much sturdier. The British Standards Institution has, in its specification BS 1263 of 1946, adopted the Luer mount for all-glass as well as metal-and-glass hypodermic syringes for general use. It is probable, therefore, that the standard for hypodermic needles will, when published, also specify the Luer fitting. It is to be hoped that, when this standard is drawn up, a rational orismological system will be advised and adopted. Such a system would improve upon the present habit of the use of manufacturers' code numbers, which often combine gauge and length of needle : in a pithy form it should give details of length of needle and gauge of cannula, type of point, and size of mount, with, if possible (but not so essential) the wall-thickness of the cannula. (There have, of course, been many other modifications to the hypodermic syringe, such as the use of rubber or leather washers on the piston; hollow pistons to contain needles or drugs; permanently fixed needles protected by covers, which could also be used to prepare injection solutions, and so on. But these are mostly side branches of the genealogical tree of the modern hypodermic syringe, and so have not been described.)

\section{Future Development}

It is difficult to foresee the future development of the syringe and needle, quite apart from the many special types which have been developed and which will no doubt be made for particular purposes, but it is interesting to speculate. Is it likely, for example, that the orthodox equipment will be replaced by the "cartridge" syringe, already familiar to dentists and of which only the needle has to be sterilized? Or will there be a return to their wartime popularity of those extremely handy, single-dose, collapsible tubes with covered, sterilized needles already attached? Or will the hypospray technique, described by-Figge (1947) and Hingson and Hughes (1947), supplant the older methods? Will the many disadvantages of this new method, such as expense, limited dosage, frequent tissue injury, and complicated maintenance be offset by its simplification of the steps necessary for sterility and its ability to overcome the fear of the needle? Is it likely that Wood's lost needle will be permanently abolished by the wide acceptance of jet injection, which is only radical departure from the method used by Dr. Alexander Wood one hundred years ago ?

At any rate, it is certain that, to oust Wood's time-tested simple, accurate, and flexible injection technique from its place of universal popularity, any new method will need to possess merit indeed.

\section{Conclusion}

It seems reasonable that, although no one individual was entirely responsible for the introduction of the method of injecting drugs into the subcutaneous tissues, Dr. Alexander Wood should be granted the major share of the credit. There is no doubt that drugs were inserted below the skin before his time, but Wood's method of injecting is the one we use to-day. True, Wood was obsessed with the idea of local action, and credit must go to Charles Hunter for turning the general systemic effects after hypodermic injection to good account. But Hunter used Wood's subcutaneous method and, calling it by its equivalent Greek name, merely extended its applicability.

So Wood, availing himself of an instrument which had been evolved for intravascular administration, performed the first subcutaneous injection shortly after 10 p.m. on November 28, 1853. He introduced the method "quietly and unobtrusively" (except for some bickering with Hunter over the question of who was the first to make use of the remote effects) and "left it to make its own way" (Brown, 1886). He made no fortune from his invention and gained little fame, for, although the method is in daily use by almost every practitioner, how many know the name of the man to whom the medical profession, and indeed mankind in general, is indebted for its introduction?

I am grateful to Dr. E. Ashworth Underwood, of the Wellcome Historical Medical Museum, for drawing my attention to the very complete historical survey of hypodermic medication by Dr. $\mathrm{N}$. Howard-Jones, from which a lot of my information has been obtained. A further interesting and detailed account of the history of injection - intravenous, subcutaneous, and intramuscular -is contained in the centenary number of the Ciba Zeitschrift (March, 1946), which is entirely devoted to Die Injektion. I would like to thank Professor W. A. Bain for many stimulating discussions and for editorial criticism, though he has forbidden me to do so. Mr. C. N. England prepared all the photographs except Figs. 1 and 3.

\section{REFERENCES}

Boyle, R. (1664). The Usefulnesse of Experimental Naturall Philosophy, Part II Essay 2, p. 48 and Postscript p. 52. 2nd ed. Oxford.

(1667). Phil. Trans., 2. 551.

Brown, T. (1886). Alexander Wood. M.D. MacNiven and Wallace, Edinburgh.

Clarck, T. (1668). Phil. Trans., 3, 672.

Comrie, J. D. (1927). History of Scottish Medicine to 1860. Wellcome Historical Medical Museum, London.

Fabritius (1667). Phil. Trans., 2, 564.

Figge, F. H. (1947). Amer. Practit., Philad., 1, 465.

Fluck, P. H. (1953). Collier's Mag.. May 30, p. 48.

Fortescue-Brickdale, J. M. (1904). Guy's Hosp. Rep., 58, 15.

Fracassati (1667). Phil. Trans., 2, 490.

Guinness, A. (1845). Dublin med. Press. 13, 196.

Hingson, R. A., and Hughes, J. G. (1947). Curr. Res. Anesth., 26. 221.

Howard-Jones, N. (1947). J. Hist. Med., 2, 201.

Hunter, C. (1859). Med. Tms Gaz., 18, 234, 310, 387; 19, 251

Keynes, G. (1949). Blood Transfusion. Wright, Bristol.

Lafargue. G. V. (1836). C.R. Acad. Sci., Paris, 3, 397.

Macht, D. I. (1916). J. Amer. med. Ass., 66, 856.

Macht, D. I. (1916). J. Amer. med. Ass., 66, 856 .
Major, J. D. (1664). Prodromus Chirurgiae Infusoriae. Linsiae. Cited by Fortescue-Brickdale (1904).

Oldenburg. H. (1665). Phil. Trans.. 1, 128

Olmsted, J. M. D. (1944). François Magendie, p. 131. Schumann, New

York.
Ovid, N. (43 B.c.). Metamorphoses, Book vii, Fable II. Translated by H. T. Riley (pp. 230-7). London, 1876.

Pfender, C. A. (1911). Wash. med. Ann., 10, 346. Cited by Macht (1916. Pravaz, C-G. (1853). C.R. Acad. Sci., Paris, 36. 88, 821. 879. Purmann. M. G. (1706). Cirurgia Curiosa. Translated by C. J. Spengell. London

Report (1853). Ass. med. J., p. 1082.

Rynd, F. (1845). Dublin med. Press, 13, 167

- (1861). Dublin Quart. J. med. Sci., 32. 13.

Schwidetzky, O. (1952). Amer. surg. Trade Ass. J., April, p. 36

Sprat, T. (1702). The History of the Royal Society of London, 2nd ed., p. 317. London.

Wood, A. (1855). Edinb. med. surg. J.. 82, 265.

(1858). British Medical Journal, p. 721 . 